\title{
Impact of IFN-Free and IFN-Based Treatment on Blood Myeloid Dendritic Cell, Monocyte, Slan-DC, and Activated T Lymphocyte Dynamics during HCV Infection
}

\author{
Serena Vita ${ }^{\mathbb{D}},{ }^{1,2}$ Paola Zuccalà, ${ }^{1}$ Stefano Savinelli, ${ }^{1}$ Claudia Mascia, ${ }^{1}$ Raffaella Rossi, ${ }^{1}$ \\ Francesco Schiavone, ${ }^{3}$ Raffaella Marocco, ${ }^{2}$ Tiziana Tieghi, ${ }^{2}$ Marco Iannetta, \\ Parni Nijhawan, ${ }^{1}$ Maria Antonella Zingaropoli, ${ }^{1}$ Gabriella d'Ettore, ${ }^{1}$ Vincenzo Vullo, ${ }^{1}$ \\ Claudio Maria Mastroianni $\left(\mathbb{D},{ }^{1} \text { and Miriam Lichtner }{ }^{1}\right)^{1}$ \\ ${ }^{1}$ Department of Public Health and Infectious Disease, Sapienza University of Rome, Italy \\ ${ }^{2}$ S.M. Goretti Hospital, Latina, Italy \\ ${ }^{3}$ Department of Molecular Medicine, Sapienza University of Rome, Italy
}

Correspondence should be addressed to Serena Vita; serena.vita@gmail.com

Received 23 May 2019; Revised 20 December 2019; Accepted 24 February 2020; Published 16 March 2020

Academic Editor: Martin Holland

Copyright ( 2020 Serena Vita et al. This is an open access article distributed under the Creative Commons Attribution License, which permits unrestricted use, distribution, and reproduction in any medium, provided the original work is properly cited.

Chronic hepatitis $\mathrm{C}$ virus infection leads to the activation of innate immunity, a key component in HCV fibrosis. In the past, the use of IFN-based treatment regimens did not permit an adequate evaluation of the impact of HCV clearance on immune cells, because of their antiviral and immunomodulatory properties. The recent development of direct-acting antiviral (DAA) therapy, which is associated with high rates of sustained virological response, enables a more accurate analysis of the immunological modifications following HCV eradication. We studied the dynamics of blood myeloid dendritic cells, monocytes, slan-DCs, and T lymphocytes during IFN-free and IFN-based regimens in hepatitis $\mathrm{C}$ virus infection.

\section{Introduction}

Worldwide, an estimated 71 million people are chronically infected with hepatitis $\mathrm{C}$ virus (HCV) [1].

Chronic HCV infection is characterized by an aberrant inflammatory response that causes $\mathrm{HCV}$-mediated liver damage, leading to progressive fibrosis, potentially resulting in cirrhosis, liver failure, and hepatocarcinoma (HCC) $[2,3]$.

$\mathrm{HCV}$ can counteract both innate and adaptive immune responses by modulating the function of several types of cells of the immune system, including monocytes (Mo), macrophages, dendritic cells (DCs), and T cells [4-8]. As a result of this, the expression profile of circulating pro- and antiinflammatory cytokines and chemokines is altered, leading to chronic infection and persistent inflammation [4-8].

Until August 2011, the commercially available treatment options for HCV infection were limited to interferon-alpha(IFN- $\alpha$-) based therapies and ribavirin (RBV) for all geno- types [9-11]. IFN- $\alpha$ has antiviral activity and also enhances $\mathrm{HCV}$-specific $\mathrm{T}$ cell responses; ribavirin, a nucleoside analogue, has a small direct activity against HCV but reduces hepatic inflammation [12]. It has been speculated that these two drugs act by modulating the immune system for HCV elimination [12].

In recent years, the introduction of several oral IFN-free direct-acting antiviral agents (DAAs) in clinical practice has proved to be a milestone in the management of HCV infection, increasing sustained virological response (SVR) rates up to $95-100 \%$ [13]. DAAs are molecules that target specific nonstructural proteins of the virus, with subsequent disruption of viral replication and spread to other cells. Since IFN-free DAA regimens specifically target various steps in the HCV life cycle, they can provide the opportunity to elucidate the relationship between HCV and the innate immune response, without the confounding effect of the IFN- $\alpha$ induced immune modulation. 
In the present study, we evaluated (i) the differences in DCs, Mo, and activated $\mathrm{T}$ cells in $\mathrm{HCV}$-infected patients according to the stage of fibrosis and genotypes; (ii) the effect of IFN-based regimens and DAA-containing regimens with or without IFN on dynamic changes in circulating levels of Mo, DCs, and activated CD4 and CD8 cells; and (iii) the role of baseline values DCs, Mo, and activated T cells in predicting therapy response in patients on IFN-based regimens.

\section{Materials and Methods}

2.1. Study Population. The study was conducted in two outpatient clinics of a single referral center (Sapienza University, Rome). The study population included 73 patients with active HCV infection who were treated according to the current Italian national guidelines for $\mathrm{HCV}$ treatment [14]. Patients had no evidence of HIV or HBV infection or decompensated liver disease. Based on treatment response, patients were classified as follows: responders (R), if they achieved SVR, defined as undetectable HCV-RNA in blood 12 weeks after the end of therapy (SVR12). The subjects who stopped treatment because of virological failure or side effects were defined as non responders (NR).

During treatment and treatment follow-up, demographic, clinical, adverse events, and virological data were collected for all participants.

Data and blood samples were collected with respect to the patient's confidentiality and privacy.

2.2. HCV-RNA and HCV Genotype Testing. Plasma HCVRNA levels were determined by RealTime PCR Roche Cobas TaqMan. HCV genotypes and subtypes $1 \mathrm{a}$ and $1 \mathrm{~b}$ were determined by Abbott RealTime HCV Genotype II.

2.3. Liver Fibrosis Assessment. Liver stiffness (measured in $\mathrm{kPa}$ ) was determined by transient elastography with the use of a FibroScan machine (Echosens). Advanced fibrosis (F4) was defined as a measure of liver stiffness (LSM) greater than or equal to $14.5 \mathrm{kPa}$; severe fibrosis (F3) was defined as a LSM value greater than or equal to 10 ; mild or no fibrosis (F0-F2) was defined as a LSM value less than $10 \mathrm{kPa}$ [15].

2.4. Sample Handling. Venous blood samples were collected from each patient into EDTA-containing tubes (Becton \pm Dickinson Systems, San Jose, CA). Patients undergoing Peg-IFN- $\alpha /$ RBV treatment plus telaprevir (TVR) or boceprevir (BOC) had their peripheral blood samples collected at baseline (T0); after 1 (T1), 3 (T2), 6 (T3), and 12 (T end) months after the start of therapy; and within 4-6 months after the end ( $\mathrm{T}$ post) or interruption of the therapy. Patients on IFN-free DAA regimens had peripheral blood samples collected at baseline (T0), 1 month after the start of T1, and 3 months after the end of the therapy (T post).

2.5. Enumeration of DCs and Monocytes. To enumerate DCs and monocytes, the same staining protocols previously described by our research group have been used $[7,16]$. The analysis of the results was performed using FlowJo software (FlowJo 9.2, Tree Star, USA). Gating strategies are shown in additional file 1 . Moreover, we stained the pDCs of 5 healthy donors in parallel with both the antibody panel used in our study (in which we identified pDC with CD123 and HLA-DR expression) and a new panel, which included BDCA-2, CD123, and HLA-DR, and we found that the two methods were equivalent.

2.6. CD4 and CD8 Activation Markers. To determine activated CD4 and CD8, the same staining protocols previously described by our research group have been used [16].

2.7. Statistical Analysis. All statistical analyses were performed using GraphPad Prism Software version 6.0 (Software MacKiev). Values are given as median and ranges (minimum and maximum values). The nonparametric Mann-Whitney test and the nonparametric Kruskal-Wallis ANOVA with Dunn's posttest were used to compare the differences in values. The nonparametric Wilcoxon matched paired test was applied to perform longitudinal analyses. All differences were considered statistically significant with $p$ values less than 0.05 .

\section{Results}

3.1. Study Population Characteristics. The study population included 73 patients; 25 were on INF-based treatment, including Peg-IFN- $\alpha / \mathrm{RBV}$ plus first-generation protease inhibitors TVR and BOC; and 54 (of which 6 had previously failed with INF-based therapy) were treated with IFN-free DAA regimens with or without RBV. The demographic and clinical features of the patients are listed in Table 1.

In the IFN-based treatment group, 13 patients (52\%) were responders and 12 (48\%) were non responders, of which $33 \%$ NR for virological failure and $67 \%$ NR for side effects.

All the 54 patients treated with IFN-free DAA regimens were responders since they reached the SVR12; clinical features of patients are listed in Table 1. Among these patients, six had previously been treated with Peg-IFN- $\alpha+\mathrm{RBV}$ and failed to achieve SVR and were retreated with an IFN-free DAA regimen after 1 year.

\subsection{Immune System Parameters at Baseline}

3.2.1. DCs and Monocytes. Patients were stratified according to the stage of fibrosis.

An increase in nonclassical $\mathrm{Mo}$ in the F0-F2 group compared to the F4 one (median cells/ml (range): 58.106 cells/ml (27.889-89.971) vs. 23.856 cells/ml (2.783-82.076); $p=0.0016)$ was observed. Slan-DCs were drastically reduced in patients with F4 fibrosis compared to F3 and F0-F1 fibrosis (3.010 cells/ml for F4 (113.6-27.946), 7.441 cells/ml for F3 (3.919-13.121), and 9.258 cells/ml for F0-F1 (3578-28968), respectively; $p=0.0020)$. Also, a trend towards a decrease in plasmacytoid DCs (pDCs) from low fibrosis to high fibrosis was observed, with significant differences between F0-F2 and F4 (6.045 cells/ml (2.726-14.257) vs. 3.862 cells $/ \mathrm{ml}$ (965.6-13746), respectively; $p=0.036)$. No significant differences were found in classical Mo, intermediate Mo, and myeloid DCs (mDCs) (Figure 1).

No significant differences were found in DCs and Mo counts in the different HCV genotypes (data not shown). 
TABLE 1: Characteristics of study population.

\begin{tabular}{|c|c|c|}
\hline & $\begin{array}{l}\text { INF-free therapy } \\
\qquad 554\end{array}$ & $\begin{array}{l}\text { INF-based therapy } \\
\qquad 25\end{array}$ \\
\hline Age, median (range) & $61(40-78)$ & $52(25-70)$ \\
\hline Sex male, $n(\%)$ & $43(80 \%)$ & $20(80 \%)$ \\
\hline \multicolumn{3}{|l|}{ Genotypes, $n(\%)$} \\
\hline 1a & $17(31 \%)$ & $8(32 \%)$ \\
\hline $1 \mathrm{~b}$ & $22(41 \%)$ & $17(68 \%)$ \\
\hline Others & $15(28 \%)$ & \\
\hline FIB-4, median (range) & $2.91(0.9-11.84)$ & $2.08(0.5-20.44)$ \\
\hline FibroScan (kPa), median (range) & $22.7(10.6-248)$ & $11.6(1.3-37.4)$ \\
\hline HCV-RNA $\left(* 10^{6} \mathrm{cp} / \mathrm{ml}\right)$, median (range) & $0.88(0.0014-3.12)$ & $2.28(0.78-7.95)$ \\
\hline ALT (UI/l), median (range) & $91(28-407)$ & $105(42-288)$ \\
\hline AST (UI/l), median (range) & $69(22-247)$ & $73(26-280)$ \\
\hline $\operatorname{PLT}\left(* 10^{9} / 1\right)$, median (range) & $139(28-340)$ & $170(34-290)$ \\
\hline Cirrhotic, $n(\%)$ & $40(70 \%)$ & $9(36 \%)$ \\
\hline \multicolumn{3}{|l|}{ Fibrosis stage } \\
\hline $\mathrm{F} 0-\mathrm{F} 2, n(\%)$ & $1(2 \%)$ & $10(40 \%)$ \\
\hline $\mathrm{F} 3, n(\%)$ & $10(19 \%)$ & $6(24 \%)$ \\
\hline $\mathrm{F} 4, n(\%)$ & $41(79 \%)$ & $9(36 \%)$ \\
\hline
\end{tabular}
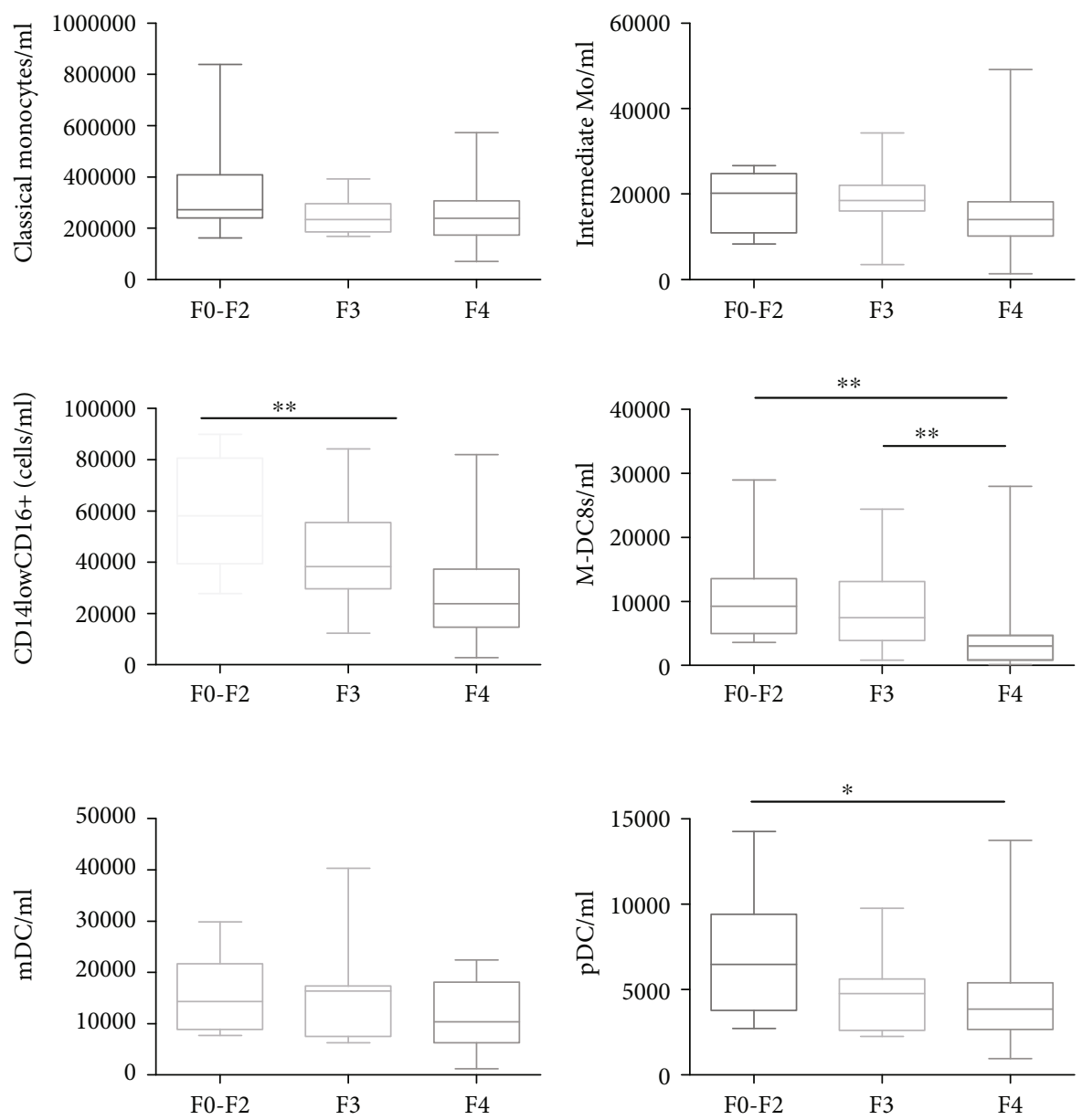

FIGURE 1: DC and monocyte count in 73 patients according to the fibrosis stage. 11 pts in the F0-F2 group, 16 in the F3 group, and 50 in the F4 group were enrolled. ${ }^{*} p<0.01,{ }^{* *} p<0.001$, and ${ }^{* * *} p<0.0001$. 

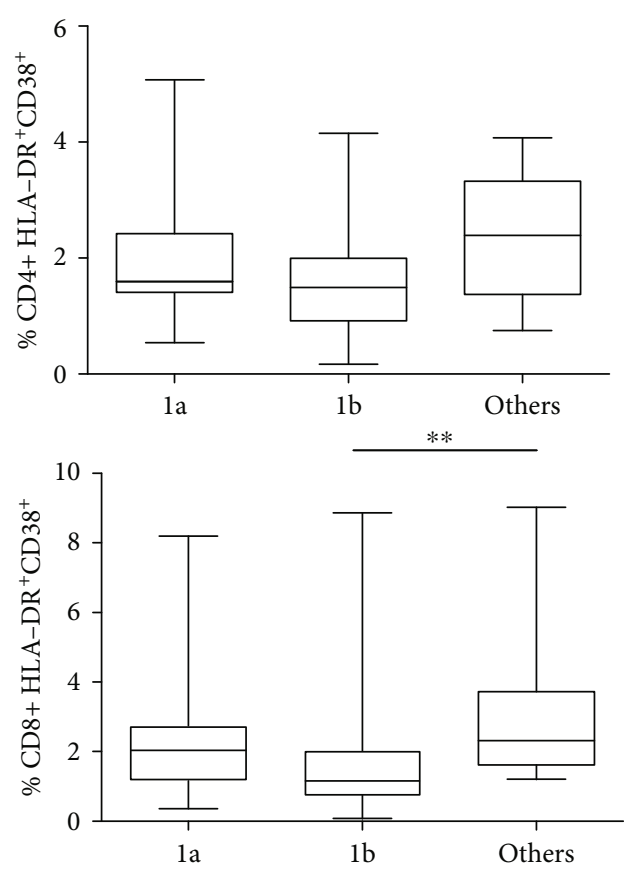

Figure 2: Activated CD4+ and CD8+ according to genotypes in all study population. 25 pts with genotype 1a, 39 pts with genotype $1 \mathrm{~b}$, and 15 pts with other genotypes were enrolled. ${ }^{*} p<0.01$, ${ }^{* *} p<0.001$, and ${ }^{* * *} p<0.0001$

3.2.2. $\mathrm{CD}^{+}$and $\mathrm{CD} 8^{+} \mathrm{T}$ Cell Activation. Regarding activated $\mathrm{CD}^{+}$and $\mathrm{CD}^{+} \mathrm{T}$ cells, we stratified patients according to the following: (i) the stage of fibrosis in which no differences were observed in activated T cells, for both $\mathrm{CD} 4^{+}$and $\mathrm{CD} 8^{+}$ $\mathrm{T}$ cells (data not shown), and (ii) genotypes in which we observed a trend towards an increase in the percentage of $\mathrm{CD}^{+}{ }^{+} \mathrm{HLA}-\mathrm{DR}^{+} \mathrm{CD} 38^{+}$in patients with other genotypes compared to genotype $1 \mathrm{~b}(2.39 \%(0.75-4.08)$ vs. $1.49 \%$ (0.17-2.39), respectively, $p=0.37)$. The median value (range) for genotype $1 \mathrm{a}$ was $1.59 \%$ (0.54-5.08). Regarding $\mathrm{CD}^{+} \mathrm{T}$ cells, we observed a significantly lower percentage of $\mathrm{CD} 8^{+}$ $\mathrm{HLA}_{-\mathrm{DR}}{ }^{+} \mathrm{CD} 38^{+} \mathrm{T}$ cells $(1.03 \%$ (0-3.2)), compared to genotype 1a $(2.85 \%(0.13-8.01))$ and other genotypes $(2.3 \%$ $(1.2-8.9))(p=0.0059)$ (Figure 2). Considering all results, patients with genotype $1 \mathrm{~b}$ showed the lowest levels of $\mathrm{CD} 4^{+}$ and $\mathrm{CD}^{+} \mathrm{T}$ cell activation.

\subsection{Dynamic Changes in Innate Immune Cells and T Cell Activation Markers during Treatment}

\subsubsection{DCs and Monocytes}

(1) INF-Based Therapy: Results. Based on the outcome of treatment, we divided the patients into three groups: responders (R) and non responders (NR) for virological failure or for side effects (Figure 3).

At baseline, an increased value in classical Mo count in $\mathrm{R}$ compared to NR for virological failure and NR for side effects was found (median cells/ml (range): 327.622 cells $/ \mathrm{ml}$ (239.355-838.879) for $\mathrm{R}$ vs. 171.934 cells/ml (161.766-
441.222) for NR for virological failure vs. $235.550 \mathrm{cells} / \mathrm{ml}$ (146.885-333.473) for NR for side effects, respectively; $p=0.0046)$.

No differences were found in intermediate Mo count between R and NR for virological failure and for side effects (18.858 cells/ml (9.770-26.696) for R vs. 9.599 cells $/ \mathrm{ml}$ (3.522-23.913) for NR for virological failure vs. 17.182 cells/ml (5.964-34.307) for NR for side effects, respectively; $p=0.056)$.

Nonclassical Mo were higher in R compared to NR for virological failure (58.958 cells/ml (15.620-89.971) vs. 27.889 cells $/ \mathrm{ml}(12.326-38.397)$ respectively; $p=0.026)$, while no difference in their count was observed compared to NR for side effects (49.104 cells/ml (17.267-74.181)).

For what concerns slan-DCs, a higher value was found in $\mathrm{R}$ compared to NR for virological failure (10.764 cells $/ \mathrm{ml}$ (2.102-28.968) vs. 3.578 cells/ml (398-6.248), $p=0.035)$; no difference was observed when comparing $\mathrm{R}$ with $\mathrm{NR}$ for side effects $(6.078$ cells/ml (2.102-17.494)).

No differences were found in the $\mathrm{mDC}$ count between the three groups. Median values and range were 16.870 cells $/ \mathrm{ml}$ (6.305-29.876) for $\mathrm{R}, 10.508$ cells/ml (5.282-14.370) for NR for virological failure, and 10.082 cells/ml (7.498-20.278) for NR for side effects, respectively.

A higher level of pDCs was found in R compared to NR for virological failure and NR for side effects $(7.412$ cells $/ \mathrm{ml}$ (4.317-14.257) for $\mathrm{R}$ vs. 2.726 cells/ml (1.022-3.181) for $\mathrm{NR}$ for virological failure vs. 4.345 cells/ml (2.215-6.134) for NR for side effects, respectively; $p=0.0006$ ).

Changes in innate immune system cell subsets from the baseline to the end of treatment were longitudinally analyzed in the three different groups, and the results are reported below.

(2) Responders. In R, classical Mo progressively decreased during therapy at $\mathrm{T} 1$ month, $\mathrm{T} 2$ month, and $\mathrm{T}$ end and slightly increased at $\mathrm{T}$ post compared to $\mathrm{T} 0$ (baseline) (Figure 4). The median value at T0 was 327.622 cells $/ \mathrm{ml}$ (239.355-838.879) compared to a value at T1 month of 200.419 cells/ml (28.911-279.513; $p=0.0005)$, at T2 month of 138.223 cells $/ \mathrm{ml}(28.911-262.359 ; p=0.001)$, at $\mathrm{T}$ end of 134.786 cells $/ \mathrm{ml}(90.526-257.190 ; p=0.0078)$, and at $\mathrm{T}$ post of 286.897 cells $/ \mathrm{ml}(91.846-405.268 ; p=0.04)$.

A slight increase in intermediate Mo was observed up to the end of treatment, and then, the values tended to drop at a slightly lower value than baseline, even though the difference was not statistically significant. The median values at the different time points were the following: T0 $18.858 \mathrm{cells} / \mathrm{ml}$ (9.770-266.696), T1 month 20.476 cells/ml (6.248-63.332), T2 month 22.834 cells/ml (3.635-74.749), T3 month 20.562 cells/ml (6.418-93.379), $\mathrm{T}$ end 21.044 cells $/ \mathrm{ml}$ (14.25740.498), and T post 2.326 cells/ml (5.623-41.521).

Regarding nonclassical Mo, a statistically significant reduction during the course of treatment between $\mathrm{T} 0$ and T1 month (58.958 cells/ml (15.620-89.971) vs. 18.460 cells/ml (4.374-35.102); $p=0.0005)$, T0 and T2 month (58.958 cells/ml (15.620-89.971) vs. 18.517 cells $/ \mathrm{ml}$ (4.60138.113); $p=0.0005)$, and $\mathrm{T} 0$ and $\mathrm{T}$ end $(58.958$ cells $/ \mathrm{ml}$ 

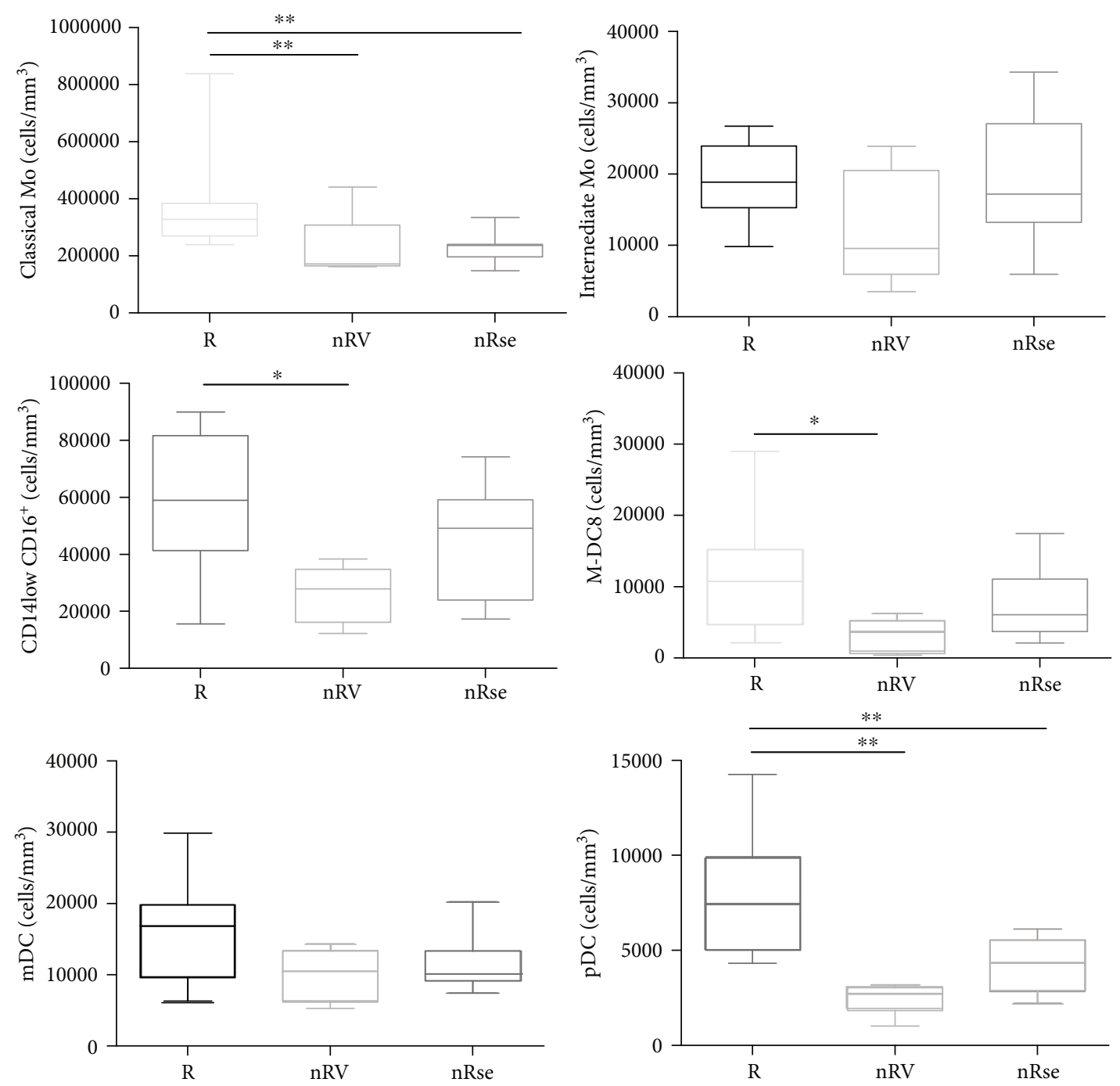

FIGURE 3: DCs and monocytes at baseline according to the response to IFN-based therapy: 13 responders (R), 4 non responders for virological failure (nRv), and 8 non responders for side effects (nRse). ${ }^{*} p<0.01,{ }^{* *} p<0.001$, and ${ }^{* * *} p<0.0001$.

(15.620-89.971) vs. 14.342 cells/ml (5.453-37.942); $p=0.00078)$ was observed, whereas values at $\mathrm{T}$ post were significantly higher than those at the end of treatment $(47712$ cells $/ \mathrm{ml}$ (21925-182498) vs. 14.342 cells/ml (5.453-37.942); $p=0.015)$.

Quite interestingly, slan-DCs were almost undetectable in peripheral blood samples after one month of treatment, with a subsequent trend towards recovery at the end of treatment and posttreatment (Figure 4). A significant difference was observed between T0 and T1 month to T3 month $(10.764$ cells $/ \mathrm{ml}(2.102-28.968)$ for $\mathrm{T} 0$ vs. 0 cells $/ \mathrm{ml}$ (0-908.8) for T1 month $(p=0.0005)$ vs. 0 cells $/ \mathrm{ml}(0-170.4)$ for T2 month $(p=0.002)$ vs. 0 cells $/ \mathrm{ml}(0-5510)$ for T3 month $(p=0.0039)$, respectively). Values at T post were significantly higher than those at T1 month to T3 month (7753 cells $/ \mathrm{ml}$ (4771-21357) vs. 0 cells/ml (0-908.8) for T1 month $(p=0.002)$ vs. 0 cells $/ \mathrm{ml}(0-170.4)$ for T2 month $(p=0.002)$ vs. 0 cells $/ \mathrm{ml}(0-5510)$ for T3 month $(p=0.008))$.

Considering mDCs, we observed a decrease up to the $12^{\text {th }}$ week of treatment, followed by an increase at week
24 and at the end of therapy. The median value at T0 was 16.870 cells $/ \mathrm{ml}$ (6.305-29.877), at $\mathrm{T} 1$ month 10.025 cells/ml (3.408-24.765), at T2 month 3.976 cells $/ \mathrm{ml}$ (965.6 to 13.121$)$, at T3 month 14.541 cells $/ \mathrm{ml}$ (10.735-33.853), at $\mathrm{T}$ end 9.684 cells $/ \mathrm{ml}(6.362-17.324)$, and at $\mathrm{T}$ post 12.496 cells/ml (5.850-19.880).

Significant differences in $\mathrm{mDC}$ values were observed between T0 and T2 month $(p=0.0005)$ and between T2 month and T3 month $(p=0.00039)$.

The pDCs significantly decreased up to six months of therapy, with a subsequent progressive increase to values similar to those before the initiation of therapy.

There was a significant decrease in pDCs between $\mathrm{T} 0$ and T1 month $(7.412$ cells $/ \mathrm{ml}(4.317-14.257)$ vs. 3.578 cells $/ \mathrm{ml}$ (738.4-6.305), respectively; $p=0.0005)$, between T0 and T2 month (2.244 cells $/ \mathrm{ml}$ (965.6-5.453), $p=0.0005)$, between T0 and T3 month (3.067 cells/ml (1.534-7.895), $p=0.0019)$, between $\mathrm{T} 0$ and $\mathrm{T}$ end $(2.499$ cells $/ \mathrm{ml}$ (1.704-6.134), $p=0.0078)$, and between $\mathrm{T} 0$ and $\mathrm{T}$ post $(4.714$ cells $/ \mathrm{ml}$ 
Classical Mo

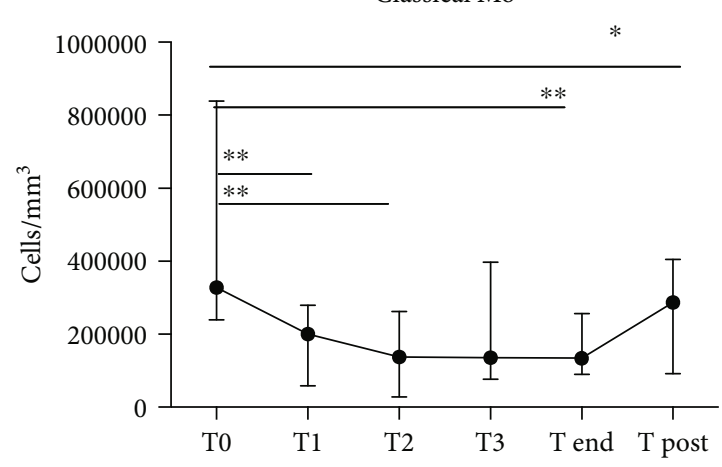

CD14 low Mo
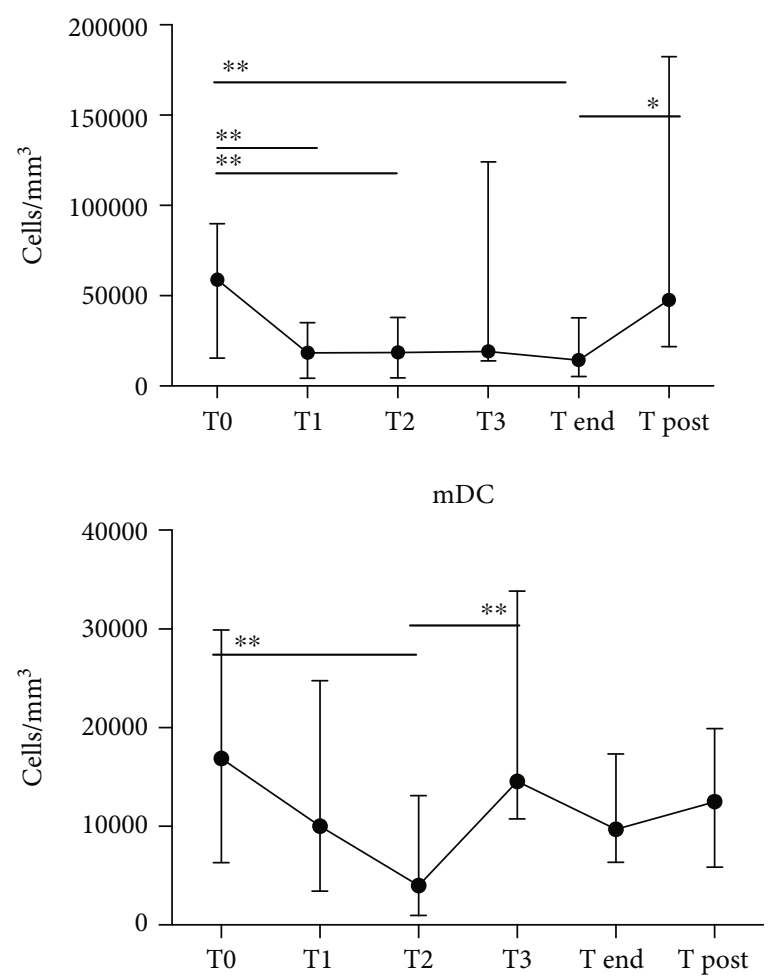
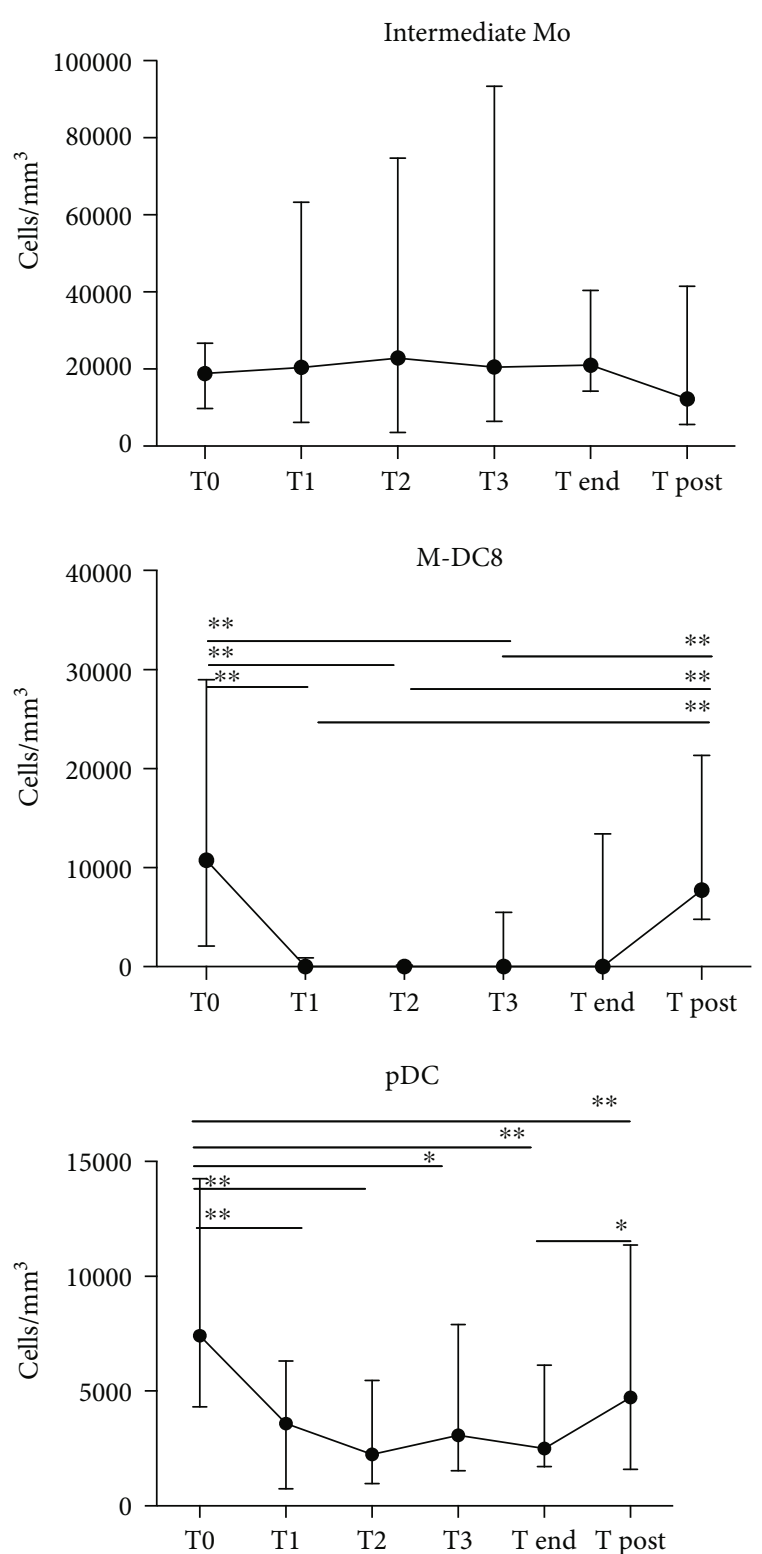

FIGURE 4: DC and monocyte dynamics during IFN-based treatment in the 13 responder patients. T0= baseline; T1 = sample after 1 month of therapy; T2 = sample after 2 months of therapy; T3=sample after 3 months of therapy; $\mathrm{T}$ end=sample after the end of therapy; T post $=$ sample 3 months after the end of the therapy. ${ }^{*} p<0.01,{ }^{* *} p<0.001$, and ${ }^{* * *} p<0.0001$.

(1.590-11.360), $p=0.0098)$. Moreover, other significant differences were observed between $\mathrm{T}$ end and T post $(p=0.0031)$.

(3) Non Responders for Virological Failure. In NR for virological failure, no differences were observed neither in all Mo subsets nor in $\mathrm{mDC}$ and $\mathrm{pDC}$ counts during treatment (see additional file 2).

(4) Non Responders for Side Effects. In NR for side effects, no differences were observed in the monocyte subsets and $\mathrm{mDC}$ and $\mathrm{pDC}$ counts during the course of treatment (see additional file 3 ).

(5) INF-Free Therapy: Results. In all the patients who underwent DAA-based regimens, we observed a progressive decrease in classical Mo during therapy at T1 month and at T post compared to T0, with a statistically significant difference only between $\mathrm{T} 0$ and $\mathrm{T}$ post $(p=0.015)$. The median value at T0 was 284.568 cells/ml (142.738-573.055), at T1 month 184.578 cells/ml (29.659-325.634), and at $\mathrm{T}$ post 128.084 cells/ml (39.135-530.798) (see additional file 4).

\subsubsection{CD4 and CD8 Activation Markers}

(1) IFN-Based Therapy. At the baseline, the percentage of CD4 and CD8 T cells did not differ between the three groups: $\mathrm{R}, \mathrm{NR}$ for virological failure, and NR for side effects. For CD4 $\mathrm{T}$ cells, the median value for $\mathrm{R}$ was $32.3 \%$ (8-32.8), for $\mathrm{NR}$ for virological failure $30.1 \%(8.8-31)$, and for NR for side effects $33.4 \%$ (9-35.9) (data not shown). For CD8 T cells, the median 

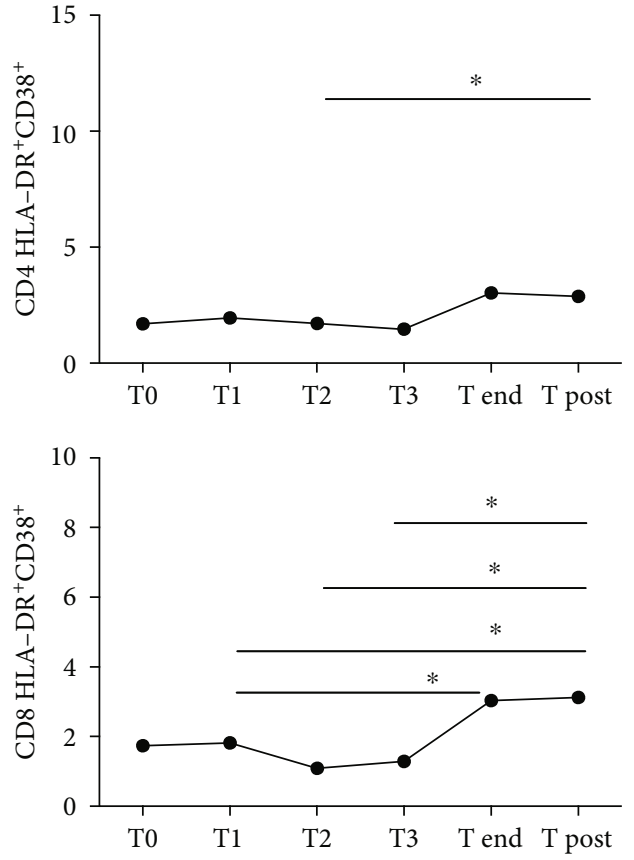

Figure 5: Activated CD4 HLA-DR ${ }^{+} \mathrm{CD} 38^{+}$and CD8 HLA$\mathrm{DR}^{+} \mathrm{CD} 38^{+}$dynamics in 25 patients under IFN-based treatment with sustained virological response. T0 $=$ baseline; $\mathrm{T} 1=$ sample after 1 month of therapy; T2 = sample after 2 months of therapy; $\mathrm{T} 3$ = sample after 3 months of therapy; $\mathrm{T}$ end = sample after the end of therapy; $\mathrm{T}$ post $=$ sample 3 months after the end of the therapy. ${ }^{*} p<0.01,{ }^{* *} p<0.001$, and ${ }^{* * *} p<0.0001$.

value for $\mathrm{R}$ was $14 \%$ (7-32), for NR for virological failure 7\% (4-22), for NR for side effects 8\% (6-18.1) (data not shown).

The percentage of activated CD4 T cells, at baseline, did not differ between the three groups ( $R, N R$ for virological failure, and NR for side effects). The median value for $\mathrm{R}$ was $1.71 \%(0.36-8.28)$, for NR for virological failure $2.22 \%$ (0.17-3.66), and for NR for side effects 1.95\% (1.4-4.42) (data not shown).

Similar results were found in $\mathrm{CD}^{+}$-activated cells, for which the median value for $\mathrm{R}$ was $1.73 \%(0.19-8.64)$, for NR for virological failure was $2.2 \%(0.08-11.11)$, and for NR for side effects was $1.59 \%$ (0.8-8.2) (data not shown).

(2) Responders. In R patients, the percentage of CD4 and CD8 $\mathrm{T}$ cells did not change during the therapy. The median value for CD4 T cells at T0 was $32.3 \%$ (8-32.8), at T1 month $30.3 \%$ (7-32), at T2 month $30.5 \%$ (7-31), at T3 month $31 \%(8-32)$, at $\mathrm{T}$ end $31.2 \%(8.5-33)$, and at $\mathrm{T}$ post $31.1 \%(8.1-31)$. Regarding CD8 T cells, the median value at T0 was $14 \%$ (7-32), at T1 month 15\% (7.1-33), at T2 month $15.1 \%$ (7-31), at T3 month $14.8 \%(8-31)$, at $\mathrm{T}$ end $14.5 \%(8.5-31)$ and $13.9 \%(7.2-31)$, and at $\mathrm{T}$ post $14 \%(7.5-32)$.

In $\mathrm{R}$ patients, we observed an overall increase in $\mathrm{CD} 4^{+}$and $\mathrm{CD} 8^{+}$-activated cells during the course of therapy, which seemed to persist even after the end of the treatment (Figure 5). The percentage of $\mathrm{CD} 4^{+} \mathrm{HLA}-\mathrm{DR}^{+} \mathrm{CD} 38^{+}$cells increased significantly between $\mathrm{T} 2$ month and the end of the therapy $(p=0.046)$, and additionally, we observed an increasing trend between T1 month and T end, between T2 month and $\mathrm{T}$ end, and between $\mathrm{T} 3$ month and $\mathrm{T}$ end. The median value at T0 was $1.65 \%(0.36-3.05)$, at T1 month $2.07 \%(1.52-3.98)$, at T2 month $2.44 \%(0.51-5.63)$, at T3 month $1.47 \%(1.15-3.21)$, at $\mathrm{T}$ end $3.28 \%(2.26-5.24)$, and at $\mathrm{T}$ post $2.85 \%(1.19-7.26)$.

The percentage of activated $\mathrm{CD}^{+} \mathrm{T}$ cells remained substantially stable during therapy up to T3 month, with the following significant increase between $\mathrm{T} 3$ month and $\mathrm{T}$ post $(p=0.015)$. Moreover, the percentage of activated CD8 ${ }^{+}$cells at T post was higher compared to that at T1 month $(p=0.046)$ and T2 month $(p=0.046)$. The median value at T0 was $1.25 \%$ (0.19-8.64), at T1 month $1.91 \%(0.7-6.27)$, at T2 month $1.35 \%$ (0.37-5.28), at T3 month $1.29 \%(0.57-4.8)$, at $\mathrm{T}$ end $3.28 \%$ (2.26-5.24), and at T post 3.91\% (1.16-8.19).

(3) Non Responders for Virological Failure. In NR patients for virological failure, the percentage of CD4 and CD8 T cells did not change during the therapy. The median value at T0 was $30.1 \%(8.8-31)$, at T1 month $29.5 \%(9-30)$, at T2 month $30 \%(8.3-29.8)$, at T3 month $30.2 \%(8-30)$, at $\mathrm{T}$ end $31.4 \%$ (8.7-32), and at $\mathrm{T}$ post $31.2 \%(8.5-31.5)$. Regarding CD8 T cells, the median value at T0 was $7 \%(4-22)$, at T1 month $7.5 \%$ (5-23), at T2 month 7.1\% (4-22), at T3 month $7.3 \%$ (5.3-19), at $\mathrm{T}$ end $7.8 \%(4.5-2)$ and $13.9 \%(6.9-22)$, and at $\mathrm{T}$ post $7.3 \%(5-22.3)$.

No differences were observed in the levels of $\mathrm{CD}^{+}$and $\mathrm{CD}^{+}$cell activation during the course of therapy. For $\mathrm{CD}^{+}{ }^{+} \mathrm{HLA}_{-}-\mathrm{DR}^{+} \mathrm{CD} 38^{+}$cells, the median value at T0 was $2.43 \%(0.17-3.66)$, at $\mathrm{T} 1$ month $1 \%(0.89-1.13)$, at T2 month $1.03 \%(0-95-1.11)$, at $\mathrm{T} 3$ month $0.57 \%(0.57-0.57)$, at $\mathrm{T}$ end $1.57 \%(1.41-2.76)$, and at $\mathrm{T}$ post $1.57 \%(1.28-2.74)$.

For $\mathrm{CD}^{+} \mathrm{HLA}^{-\mathrm{DR}}{ }^{+} \mathrm{CD} 38^{+}$cells, the median value at T0 was $2.82 \%(0.08-11.11)$, at T1 month $0.43 \%(0.27-0.68)$, at T2 month $0.6 \%(0.18-1.03)$, at T3 month $0.75 \%(0.75-0.75)$, at $\mathrm{T}$ end $3.46 \%(2.82-4.11)$, and at $\mathrm{T}$ post $1.71 \%(0.83-3.63)$ (data not shown).

(4) Non Responders for Side Effects. In NR patients for side effects, the percentage of CD4 and CD8 T cells did not change during the therapy. The median value for CD4 T cells at T0 was $33.4 \%$ (9-35.9), at T1 month $32.3 \%(9.3-34)$, at T2 month $32.5 \%$ (9.1-34.5), at T3 month $32 \%$ (9.3-34), at T end $33.2 \%(8.5-34)$, and $33 \%(9.1-35.2)$ at $\mathrm{T}$ post.

Regarding CD8 T cells, the median value at T0 was $8 \%$ (6-18.1), at T1 month $8.2 \%(6.3-17.6)$, at T2 month $7.9 \%$ (5.9-17.4), at T3 month $8.1 \%(6-18)$, at T end $7.9 \%(6.5-19)$ and $7.9 \%(6.9-18)$, and at $\mathrm{T}$ post $7.9 \%(6.2-19)$.

A significant difference in the percentage of $\mathrm{CD} 4^{+} \mathrm{HLA}-$ $\mathrm{DR}^{+} \mathrm{CD} 38^{+}$cells was observed between $\mathrm{T} 0$ and $\mathrm{T}$ post $(1.95 \%$ $(1.4-4.42)$ vs. $2.62 \%(1.68-6.52), p=0.015)$. The median percentage at T1 month was $0.69 \%(0.56-1.64)$, at T2 $2.07 \%$ (1.14-3.65), and at T3 month $2.39 \%$ (2.39-2.64).

No differences in the percentage of $\mathrm{CD}^{+} \mathrm{HLA}^{+} \mathrm{DR}^{+-}$ CD $38^{+}$cells were found. The median value at T0 was $1.59 \%$ (0.8-8.2), at T1 month $1.72 \%(0.52-2.59)$, at T2 month $5.4 \%$ 

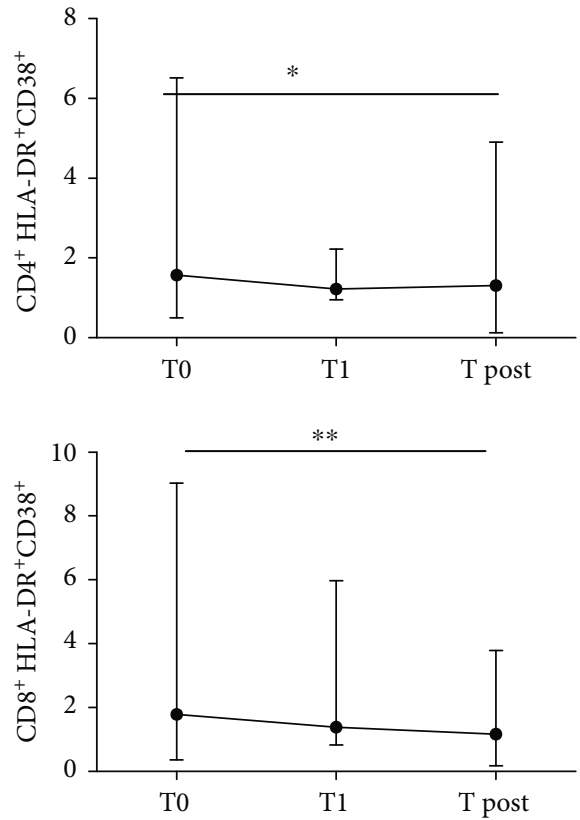

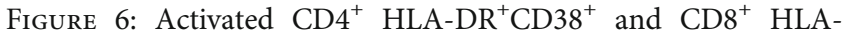
$\mathrm{DR}^{+} \mathrm{CD} 38^{+}$dynamics in 54 patients under IFN-free treatment. T0 = baseline; T 1 = sample after 1 month of therapy; $\mathrm{T}$ post $=$ sample after 3 months the end of the therapy. ${ }^{*} p<0.01,{ }^{* *} p<0.001$, and ${ }^{* * *} p<0.0001$.

(2.3-8.78), at T3 month 9.04\% (9.04-10.04), and at $\mathrm{T}$ post $2.05 \%(1.29-8.94)$ (data not shown).

(5) INF-Free Therapy. During the therapy, the percentage of CD4 and CD8 T cells did not change (data not shown). For CD4 T cells, the median value was 30.6\% (5-53.5) while for CD8 T cells, the median value was $15.1 \%$ (2-25). During therapy, no changes in CD4 and CD8 T cells were observed. For CD4 T cells, the median value at T0 was $30.6 \%(5-53.5)$, at T1 month $30.1 \%(5.2-52)$, and at T post $30.2 \%$ (5.6-53). For CD8 $\mathrm{T}$ cells, the median value at T0 was $15.1 \%(2-25)$, at T1 month $15.5 \%(2.4-24)$, and at $\mathrm{T}$ post $15.2 \%(2.3-24.5)$.

The percentage of $\mathrm{CD} 4^{+} \mathrm{HLA}-\mathrm{DR}^{+} \mathrm{CD} 38^{+}$cells during treatment remained almost constant, with a slight decrease at $\mathrm{T}$ post $(1.31 \%(0.13-4.9))$ compared to $\mathrm{T} 0 \quad(1.59 \%$ $(0.5-6.5))(p=0.045)$. The median value at T1 month was $1.36 \%(0.98-2.93)$.

A greater decrease between T0 1.72\% (0.36-9.02) and T post $1.19 \%(0.17-4.18)$ was observed in $\mathrm{CD} 8^{+}$-activated cells $(p=0.0038)$. The median value at $\mathrm{T} 1$ month was $1.4 \%$ (0.83-8.59) (Figure 6).

\section{Discussion}

The last few years have seen extraordinary advances in the management of patients with chronic HCV infection.

The use of a triple therapy which combined firstgeneration DAAs with pegylated interferon (Peg-IFN) and ribavirin (RBV) significantly improved the chances of achieving sustained virological response (SVR) rates to over
$60 \%$. However, treatment with telaprevir and boceprevir was intended for genotype $1 \mathrm{HCV}$-infected patients and antiviral potency was counteracted by considerable side effects, in particular an increased number of bacterial infections $[17,18]$.

In our study, patients undergoing IFN-based therapy showed a successful rate of $67 \%$ in accordance with what is known from the literature [19, 20].

In almost half of nonresponder patients, the interruption of therapy was mainly due to neutropenia and infectious diseases (sepsis and pneumonia), in line with previous reports of the association with an increase in treatment-related adverse events compared to the former standard therapy without protease inhibitors. The mechanism of this increased susceptibility to infections seems to be related to the in vitro inhibition of neutrophil elastase activity [21, 22].

IFN-free treatments consisting of combinations of second-generation DAAs, with or without ribavirin, showed impressive SVR rates and a safer profile. In our cohort, the success rate was $100 \%$ and no patients interrupted the therapy for virological failure or for adverse effects.

In the present study, we evaluated the differences in DCs, Mo, and activated $\mathrm{T}$ cells in all $\mathrm{HCV}$-infected patients according to fibrosis stage and genotype.

The innate immune system plays a pivotal role in the host-virus interactions during the entire natural course of the disease, and IFNs are the central cytokines responsible for the induction of an antiviral state in cells and for the activation and regulation of the cellular components of innate immunity [23]. IFN- $\alpha$ has potent antiviral activity, and it acts by inducing IFN-stimulated genes (ISGs), which establish a non-virus-specific antiviral state within the cell [24]. Exogenously supplied recombinant IFN- $\alpha$ binds to and activates cellular receptors, leading to the same response as with the endogenous one.

Dendritic cells (DCs) are professional antigen-presenting cells (APCs), playing a key role in the innate immune system in orchestrating the quality and potency of downstream adaptive immune response, through the uptaking and processing of viral antigens, as well as by releasing cytokines to efficiently prime both $\mathrm{CD}^{+}$helper $\mathrm{T}$ cells and $\mathrm{CD}^{+}$cytotoxic T lymphocytes (CTLs) [25].

Two major subsets of DCs can be readily purified from human peripheral blood: plasmacytoid (p)DCs and conventional or myeloid (m)DCs [25]. pDCs and mDCs differ markedly in their ability to capture, process, and present antigens; express costimulatory molecules; and produce cytokines [26].

Slan-DCs are a third subset of DCs that were identified in peripheral blood using the monoclonal antibody M-DC8, which binds to 6-sulfo LacNac (slan), a carbohydrate moiety of the $\mathrm{P}$ selectin glycoprotein ligand 1 (PSGL-1) [27]. However, on a two-dimensional flow cytometry dot plot of CD14 and CD16 expression in peripheral blood mononuclear cells (PBMCs), slan-DCs in part overlap with CD $14{ }^{\text {dim }} \mathrm{CD} 16^{+}$monocytes [28], suggesting that they might actually represent a subset of nonclassical monocytes [29].

Regarding their function, blood slan-DCs have been described as potent proinflammatory cells, based on their 
ability to produce large amounts of tumor necrosis factoralpha (TNF- $\alpha$ ) and IL-12p70 upon stimulation with tolllike receptor (TLR) ligands [28].

In our study, all HCV-infected patients were analyzed in relation to the stage of fibrosis. Interestingly, an increase in nonclassical Mo, slan-DCs, and pDCs in peripheral blood was found in patients with low fibrosis compared with those with high fibrosis. This could reflect a higher level of these cells in peripheral blood during the early stages of fibrosis, followed by a reduction due to their migration to the liver when fibrosis is progressing. Indeed, peripheral blood monocytes constantly enter the liver to replenish hepatic macrophages, and the number of infiltrating monocytes increases during liver inflammation and modulates fibrogenesis [30]. In fact, during fibrogenesis, there is an infiltration of leukocytes and monocytes/macrophages into the liver; this infiltration is the key for the activation of hepatic stellate cells and subsequent fibrosis; moreover, reducing liver-infiltrating macrophages, it is possible to attenuate fibrosis in some models [30]. During HCV infection, there is a continuous recruitment of monocytes and macrophages into the liver where under local signals became able to secrete a variety of proinflammatory, profibrotic, and anti-inflammatory cytokines and growth factors [29].

Monocytes are attracted to the site of infection and are exposed to viral RNA and protein, which can lead to their activation $[31,32]$. Nonclassical monocytes $\left(\mathrm{CD} 14^{++} \mathrm{CD} 16^{+}\right)$ preferentially accumulate in the chronically inflamed human liver as a consequence of enhanced recruitment from blood and local differentiation from classical $\mathrm{CD} 14^{++} \mathrm{CD} 16^{-}$monocytes [29]. Nonclassical monocytes are major modulators of fibrogenesis in the liver producing profibrogenic cytokines and chemokines. Mascia et al. recently [8] described how monocyte-derived cytokines such as CXCL-10 and sCD14 are increased in all stages of fibrosis, underlying the presence of immune activation from F0 to F4 [8, 33]. Slan-DCs seem to contribute to the pathogenesis of chronic inflammatory diseases such as Crohn's disease, rheumatoid arthritis, psoriasis, and HIV since they infiltrate the inflamed ileal mucosa, skin, and synovial tissue $[16,28,34]$. They are a major source of tumor necrosis factor- $\alpha$, a pleiotropic cytokine produced even by macrophages/monocytes in response to bacterial LPS, and are significantly expanded in patients with bacterial sepsis [34]. TNF- $\alpha$ has been implicated in the pathogenesis of chronic liver inflammation-activating resident HSCs into fibrogenic myofibroblasts. However, there are currently no data on the possible migration of slan-DCs into the inflamed liver during the progress of fibrosis. The subset of plasmacytoid DCs (pDCs) is considered to be the front line in antiviral immunity, owing to the rapid production of high amounts of type I interferon in response to viruses [35]. Patients with chronic HCV infection have a reduced ability to produce INF after in vitro stimulation of pDCs due to a decrease in their absolute number, an impairment in their function, and an increase in their homing to the liver [32].

Various studies have shown that $\mathrm{CD} 4^{+}$helper $\mathrm{T}$ cell- and $\mathrm{CD}^{+}$cytotoxic $\mathrm{T}$ cell-mediated immune responses determine the outcome of HCV infection. Thus, spontaneous viral clearance of HCV infection is characterized by vigorous and sustained specific $\mathrm{CD}^{+}$and $\mathrm{CD} 8^{+} \mathrm{T}$ cell responses during the acute phase of infection, while in contrast chronic infection is correlated with late, transient, weak, or narrowly focused $\mathrm{CD}^{+}$and $\mathrm{CD}^{+} \mathrm{T}$ cell responses $[36,37]$.

We focused our analysis on activated $\mathrm{CD} 4^{+}$and $\mathrm{CD} 8^{+}$ cells, and interestingly no differences in activated $\mathrm{CD} 4^{+}$and $\mathrm{CD}^{+}$were found in $\mathrm{HCV}$-infected patients stratified for fibrosis stage. Regarding different genotypes, a lower activation of $\mathrm{CD}^{+}$cells was observed in patients with genotype $1 \mathrm{~b}$ compared to other genotypes. Genotype $1 \mathrm{~b}$ has historically been associated with a lower likelihood of selection of resistant variants and a better response to IFN-based therapy, compared to other genotypes [38]. In this setting, the lower impact on the activation of peripheral $\mathrm{CD}^{+}$cells can have an impact on the response to treatment.

To investigate the effect of IFN-based regimens and DAA-containing regimens with or without IFN on dynamic changes in circulating levels of monocytes (Mo) and DCs and activated CD4 and CD8 cells, we performed a longitudinal study.

During the course of INF-based regimens, we observed a decrease in pDCs after 1 month of therapy, which persisted up to the end of therapy, with subsequent increase after the interruption of treatment, although without a restoration to pretreatment values. mDCs tended to remain stable over the treatment course, although a decrease in number was observed at month 3 , followed by a recovery at month 6 .

No differences in both pDCs and mDCs were found in patients who failed due to virological failure or side effects.

Regarding monocytes, a decrease in classical monocytes, nonclassical monocytes, and slan-DCs was observed after 1 month of therapy that persisted after 6 months. No differences were observed in non responders.

These variations in the levels of circulating innate immune cells could be a consequence of the IFN-induced depression of bone marrow activity, as suggested by the well-known reduction in granulocytes during treatment [39], and could explain the increased risk of bacterial infections observed in our study population.

On the other hand, DAA therapy lacks the immunomodulatory effects of IFN, possibly explaining the absence of differences in DCs and Mo counts during interferon-free treatments.

To address the dynamics of immune activation in HCV infection, we analyzed CD38 and HLA-DR expression on the $\mathrm{CD}^{+}$and $\mathrm{CD}^{+} \mathrm{T}$ cells during the two different treatments.

Both responders and non responders for side effects had increased levels of activation of $\mathrm{CD} 4^{+}$cells over the course of IFN-based therapy, which remained persistently elevated even after the end of treatment in non responders for side effects, while no alterations were observed in non responders for virological failure. On the other hand, the percentage of activated CD8+ cells was significantly increased only in responders during the course of IFN-based regimens.

Our results are in contrast with previously published data on the decrease in immune activation in the T cell compartment after IFN-based therapy [40]. However, Radkowski et al. reported increased levels of immune activation 
associated with persistence of HCV-RNA in PBMCs after successful treatment of chronic HCV infection, which could be linked to an increased risk of developing immunemediated extrahepatic complications of $\mathrm{HCV}$ infection in some patients [41].

On the contrary, during the course of DAA-based regimens, we observed a decrease in activated $\mathrm{CD}^{+} \mathrm{T}$ cells after the end of therapy. This highlights the importance of immune activation in the pathogenesis of chronic HCV infection, considering the reduced immune activation following complete viral clearance as a consequence of successful treatment with DAAs.

Finally, the observation of a higher number of classical and nonclassical monocytes, together with increased levels of pDCs and slan-DCs in responders, could suggest a possible role of the evaluation of these cell subsets in predicting treatment response during the course of IFN-based regimens. In fact, those cell subsets are involved in the immune response to HCV and have been found in peripheral blood and in the liver of patients with chronic HCV, suggesting a primary role in the immune response to the virus $[31,34,35]$. Thus, higher levels of these subpopulations of cells of the innate immune system might enhance the response against the virus and facilitate its eradication.

There are several limitations in our study. Firstly, we did not evaluate the functional status of circulating monocytes and DCs, since the analysis was limited to numerical changes in peripheral blood samples. Moreover, HCVinfected patients were not treated with the same DAA regimen, and this may have had an impact on the results, due to the possibility of differential effects of the various DAAs on immune function.

Taken together, these results could suggest that increased circulating levels of specific cell subsets within the innate immune compartment could promote antiviral response during the course of IFN-based regimens and could help in predicting the outcome of treatment in some patients.

\section{Data Availability}

All data used to support the findings of this study are included within the article and in the additional materials.

\section{Conflicts of Interest}

The authors declare that there is no conflict of interest regarding the publication of this article.

\section{Supplementary Materials}

Supplementary 1. Additional File 1: gating strategy for DCs and monocytes.

Supplementary 2. Additional File 2: DC and monocyte count in virologically nonresponder patients during IFN-based treatment.

Supplementary 3. Additional File 3: DC and monocyte count in nonresponder patients for side effects during IFN-based treatment.
Supplementary 4. Additional File 4: DC and monocyte count in patients under IFN-free treatment.

\section{References}

[1] World Health Organization, Global Hepatitis Report: WHO report 2017, WHO, Geneva, Switzerland, 2017.

[2] A. A. Negash, H. J. Ramos, N. Crochet et al., "IL-1 $\beta$ production through the NLRP3 inflammasome by hepatic macrophages links hepatitis $C$ virus infection with liver inflammation and disease," PLoS Pathogens, vol. 9, no. 4, article e1003330, 2013.

[3] C. M. Mastroianni, M. Lichtner, C. Mascia, P. Zuccalà, and V. Vullo, "Molecular mechanisms of liver fibrosis in HIV/HCV coinfection," International Journal of Molecular Sciences, vol. 15, no. 6, pp. 9184-9208, 2014.

[4] C. Caussin-Schwemling, C. Schmitt, and F. Stoll-Keller, "Study of the infection of human blood derived monocyte/macrophages with hepatitis C virus in vitro," Journal of Medical Virology, vol. 65, no. 1, pp. 14-22, 2001.

[5] G. Szabo, S. Chang, and A. Dolganiuc, "Altered innate immunity in chronic hepatitis C infection: cause or effect?," Hepatology, vol. 46, no. 4, pp. 1279-1290, 2007.

[6] R. Thimme, M. Binder, and R. Bartenschlager, "Failure of innate and adaptive immune responses in controlling hepatitis C virus infection," FEMS Microbiology Reviews, vol. 36, no. 3, pp. 663-683, 2011.

[7] C. Mascia, M. Lichtner, P. Zuccalà et al., "Active HCV infection is associated with increased circulating levels of interferon-gamma (IFN- $\gamma$ )-inducible protein-10 (IP-10), soluble CD163 and inflammatory monocytes regardless of liver fibrosis and HIV coinfection," Clinics and Research in Hepatology and Gastroenterology, vol. 41, no. 6, pp. 644-655, 2017.

[8] C. Mascia, S. Vita, P. Zuccalà et al., "Changes in inflammatory biomarkers in $\mathrm{HCV}$-infected patients undergoing direct acting antiviral-containing regimens with or without interferon," PLoS One, vol. 12, no. 6, article e0179400, 2017.

[9] P. Y. Kwo, E. J. Lawitz, J. McCone et al., "Efficacy of boceprevir, an NS3 protease inhibitor, in combination with peginterferon alfa- $2 \mathrm{~b}$ and ribavirin in treatment-naive patients with genotype 1 hepatitis C infection (SPRINT-1): an open-label, randomised, multicentre phase 2 trial," The Lancet, vol. 376, no. 9742, pp. 705-716, 2010.

[10] F. Poordad, J. McCone Jr., B. R. Bacon et al., "Boceprevir for untreated chronic HCV genotype 1 infection," The New England Journal of Medicine, vol. 364, no. 13, pp. 1195-1206, 2011.

[11] J. G. McHutchison, G. T. Everson, S. C. Gordon et al., "Telaprevir with peginterferon and ribavirin for chronic HCV genotype 1 infection," The New England Journal of Medicine, vol. 360, no. 18, pp. 1827-1838, 2009.

[12] E. Barnes, M. Salio, V. Cerundolo et al., "Impact of alpha interferon and ribavirin on the function of maturing dendritic cells," Antimicrobial Agents and Chemotherap, vol. 48, no. 9, pp. 3382-3389, 2004.

[13] M. Bourlière, V. Oules, C. Ansaldi, X. Adhoute, and P. Castellani, "Sofosbuvir as backbone of interferon free treatments," Digestive and Liver Disease, vol. 46, Supplement 5, pp. S212-S220, 2014.

[14] Documento di indirizzo dell'Associazione Italiana per lo Studio del Fegato per l'uso razionale dei farmaci anti-HCV disponibili in Italia, 2018, https://www.webaisf.org/documento-hcv2018/ last access 11.03.2020. 
[15] V. de Lédinghen, C. Douvin, A. Kettaneh et al., "Diagnosis of hepatic fibrosis and cirrhosis by transient elastography in HIV/hepatitis C virus-coinfected patients," Journal of Acquired Immune Deficiency Syndromes, vol. 41, no. 2, pp. 175-179, 2006.

[16] M. Lichtner, R. Rossi, S. Vita et al., "Blood myeloid dendritic cells and slanDC in antiretroviral therapy- suppressed HIVinfected patients," Current HIV Research, vol. 14, no. 4, pp. 331-339, 2016.

[17] J. L. Calleja, J. M. Pascasio, B. Ruiz-Antorán et al., "Safety and efficacy of triple therapy with peginterferon, ribavirin and boceprevir within an early access programme in Spanish patients with hepatitis C genotype 1 with severe fibrosis: SVRw12 analysis," Liver International, vol. 35, no. 1, pp. 90-100, 2015.

[18] C. Hezode, H. Fontaine, C. Dorival et al., "Effectiveness of telaprevir or boceprevir in treatment-experienced patients with HCV genotype 1 infection and cirrhosis," Gastroenterology, vol. 147, no. 1, pp. 132-142.e4, 2014.

[19] J. C. Price, R. C. Murphy, V. A. Shvachko, M. P. Pauly, and M. M. Manos, "Effectiveness of telaprevir and boceprevir triple therapy for patients with hepatitis $C$ virus infection in a large integrated care setting," Digestive Diseases and Sciences, vol. 59, no. 12, pp. 3043-3052, 2014.

[20] K. J. Wilby, N. Partovi, J. A. Ford, E. Greanya, and E. M. Yoshida, "Review of boceprevir and telaprevir for the treatment of chronic hepatitis C," Canadian Journal of Gastroenterology and Hepatology, vol. 26, no. 4, pp. 205-210, 2012.

[21] S. D. Seiwert, S. W. Andrews, Y. Jiang et al., "Preclinical characteristics of the hepatitis C virus NS3/4A protease inhibitor ITMN-191 (R7227)," Antimicrobial Agents and Chemotherapy, vol. 52, no. 12, pp. 4432-4441, 2008.

[22] P. W. White, M. Llinas-Brunet, M. Amad et al., "Preclinical characterization of BI 201335, a C-terminal carboxylic acid inhibitor of the hepatitis C virus NS3-NS4A protease," Antimicrobial Agents and Chemotherapy, vol. 54, no. 11, pp. 46114618, 2010.

[23] D. B. Stetson and R. Medzhitov, "Type I interferons in host defense," Immunity, vol. 25, no. 3, pp. 373-381, 2006.

[24] G. C. Sen, "Viruses and interferons," Annual Review of Microbiology, vol. 55, pp. 255-281, 2001.

[25] J. Banchereau and R. M. Steinman, "Dendritic cells and the control of immunity," Nature, vol. 392, no. 6673, pp. 245252, 1998 .

[26] W. Barchet, M. Cella, and M. Colonna, "Plasmacytoid dendritic cells-virus experts of innate immunity," Seminars of Immunology, vol. 17, no. 4, pp. 253-261, 2005.

[27] K. Schäkel, E. Mayer, C. Federle, M. Schmitz, G. Riethmüller, and E. P. Rieber, "A novel dendritic cell population in human blood: one-step immunomagnetic isolation by a specific $\mathrm{mAb}$ (M-DC8) and in vitro priming of cytotoxic T lymphocytes," European Journal of Immunology, vol. 28, no. 12, pp. 40844093, 1998.

[28] K. Schäkel, M. von Kietzell, A. Hänsel et al., "Human 6-sulfo LacNAc-expressing dendritic cells are principal producers of early interleukin-12 and are controlled by erythrocytes," Immunity, vol. 24, no. 6, pp. 767-777, 2006.

[29] E. Liaskou, H. W. Zimmermann, K. K. Li et al., "Monocyte subsets in human liver disease show distinct phenotypic and functional characteristics," Hepatology, vol. 57, no. 1, pp. 385-398, 2013.
[30] M. Imamura, T. Ogawa, Y. Sasaguri, K. Chayama, and H. Ueno, "Suppression of macrophage infiltration inhibits activation of hepatic stellate cells and liver fibrogenesis in rats," Gastroenterology, vol. 128, no. 1, pp. 138-146, 2005.

[31] J. Cros, N. Cagnard, K. Woollard et al., "Human CD14 dim monocytes patrol and sense nucleic acids and viruses via TLR7 and TLR8 receptors," Immunity, vol. 33, no. 3, pp. 375-386, 2010.

[32] A. Dolganiuc, O. Norkina, K. Kodys et al., "Viral and host factors induce macrophage activation and loss of toll-like receptor tolerance in chronic hcv infection," Gastroenterology, vol. 133, no. 5, pp. 1627-1636, 2007.

[33] A. I. Romero, M. Lagging, J. Westin et al., "Interferon (IFN)gamma-inducible protein-10: association with histological results, viral kinetics, and outcome during treatment with pegylated IFN-alpha $2 \mathrm{a}$ and ribavirin for chronic hepatitis $\mathrm{C}$ virus infection," The Journal of Infectious Diseases, vol. 194, no. 7, pp. 895-903, 2006.

[34] A. de Baey, I. Mende, G. Baretton et al., "A subset of human dendritic cells in the $T$ cell area of mucosa-associated lymphoid tissue with a high potential to produce TNF- $\alpha$," The Journal of Immunology, vol. 170, no. 10, pp. 5089-5094, 2003.

[35] F. P. Siegal, N. Kadowaki, M. Shodell et al., "The nature of the principal type 1 Interferon-Producing cells in human blood," Science, vol. 284, no. 5421, pp. 1835-1837, 1999.

[36] F. Lechner, D. K. Wong, P. R. Dunbar et al., "Analysis of successful immune responses in persons infected with hepatitis $\mathrm{C}$ virus," Journal of Experimental Medicine, vol. 191, no. 9, pp. 1499-1512, 2000.

[37] H. Wedemeyer, X. S. He, M. Nascimbeni et al., "Impaired effector function of hepatitis $\mathrm{C}$ virus-specific $\mathrm{CD} 8^{+} \mathrm{T}$ cells in chronic hepatitis C virus infection," Journal of Immunology, vol. 169, no. 6, pp. 3447-3458, 2002.

[38] D. L. Wyles, "Antiviral resistance and the future landscape of hepatitis C virus infection therapy," The Journal of Infectious Diseases, vol. 207, Supplement 1, pp. S33-S39, 2013.

[39] M. P. Manns, H. Wedemeyer, and M. Cornberg, "Treating viral hepatitis C: efficacy, side effects, and complications," Gut, vol. 55, no. 9, pp. 1350-1359, 2006.

[40] V. D. Gonzalez, K. Falconer, K. G. Blom et al., "High levels of chronic immune activation in the T-cell compartments of patients coinfected with hepatitis $\mathrm{C}$ virus and human immunodeficiency virus type 1 and on highly active antiretroviral therapy are reverted by alpha interferon and ribavirin treatment," Journal of Virology, vol. 83, no. 21, pp. 11407-11411, 2009.

[41] M. Radkowski, J. Opoka-Kegler, K. C. Cortes et al., "Evidence for immune activation in patients with residual hepatitis $\mathrm{C}$ virus RNA long after successful treatment with IFN and ribavirin," The Journal of General Virology, vol. 95, no. 9, pp. 2004-2009, 2014. 